\title{
Effect of Femtosecond Laser Impulses for Metallic Glass Magnetic Properties during Laser Cutting Processes
}

\author{
Z. WeLtSCH* \\ Department of Materials Technology, John von Neumann University, \\ Izsáki street 10, H-6000 Kecskemét, Hungary
}

\begin{abstract}
Advanced and new magnetisable materials such as METGLAS ( $\left.\mathrm{Fe}_{78} \mathrm{Si}_{9} \mathrm{~B}_{13}\right)$ metal glass ribbon have very good magnetic properties. However, production of these material is very difficult, because the manufacturing processes like cutting can damage the magnetic properties of the material. The cutting process can be carried out with waterjet, punching tools, or even a plate cutter, but in case of mechanical cutting due to the plastic deformation the amorphous structure might change. High-energy laser beam technology can provide a solution to this. Conventional $\mathrm{CO}_{2}$ lasers and other continuous-wave laser technologies are inadequate because they introduce too much heat into the structure of the material. This problem can be solved by cutting with a femtosecond laser pulses, so the microstructure and the surface of the cutting side do not change. This allows the raw material magnetic properties to be preserved for use. In this paper, different femtosecond laser cutting parameters are presented, as well as, the results of the samples magnetization after the cut.
\end{abstract}

DOI: 10.12693/APhysPolA.137.858

PACS/topics: METGLAS, electric motors, femtosecond laser

\section{Introduction}

In the last two decades wide range of Fe-based metallic glasses have been developed due to their preferential properties such as high strength, good magnetic properties and low material cost [1-5]. Nowadays more and more application requires the promising mechanical and magnetic properties of metallic glasses [6].

Recently an attempt is made to apply the soft magnetic glassy tapes to build stator and rotor elements for electric motors. The reason why these alloys are in the focus of interest is the tendencies in electric motor efficiency requirements [7].

Accordingly to [8], the soft magnetic (Fe-based) glassy alloys are good candidates for this purpose, because of their favorable hysteresis loss, especially at high frequency (already at around 1-2 kHz).

\section{Experimental}

The well known Fe based metallic glasses METGLAS glassy tapes $\left(\mathrm{Fe}_{78} \mathrm{Si}_{9} \mathrm{~B}_{13}\right)$ are investigated experimentally. The prepared samples have width of $100 \mathrm{~mm}$ and thickness of $30 \mu \mathrm{m}$.

The laser cutting process was performed using a Coherent Monaco Femtosecond Laser of wavelength $1035 \mathrm{~nm}$, of the impuls width of $300 \mathrm{fs}$, the frequency of laser impuls of $188 \mathrm{kHz}$, and the average power

\footnotetext{
* corresponding author; e-mail:

weltsch.zoltan@gamf .uni-neumann.hu
}

of $40 \mathrm{~W}$. The cutting speed (i.e., the movement speed of the laser beam using scanner optics) was set between $0.1 \mathrm{~m} / \mathrm{s}$ and $30 \mathrm{~m} / \mathrm{s}$. The cutting process was performed from 1 and 1200 times to cut out the sample properly. The laser beam was focused on the surface with a diameter of $80 \mu \mathrm{m}$. The protective atmosphere in a chamber with the sample assured 6.0 Ar gas.

Magnetic parameters of the samples were determined using magnetometer by measuring stray fields of the sample [9-10]. From the large loop of magnetic parameters we obtained: magnetic polarization of saturation measured in magnetic field of $15 \mathrm{kA} / \mathrm{m}\left(J_{s}\right)$, coercivity $\left(H_{c}\right)$, and anisotropic constant $K_{i}\left[\mathrm{~J} / \mathrm{m}^{3}\right]$. The tension anisotropic constant $K_{\sigma}$ was also determined, from the area above the curve of initial magnetic polarization.

\section{Results and discussion}

In the first step of experiment, we had to determine the cutting parameters that would be suitable for the cutting technology of metal glass strips. Productive solutions had to be found for their practical applications. In addition, we had to meet the requirements in terms of dimensional accuracy if we wanted to use electric motors. The last but not the least important aspect was to not initiate the crystallization during the cutting process. Thus, the good magnetic properties of the raw material were maintained.

One can give the two relevant variable parameters on the femtosecond laser, i.e., the power and the speed of movement. Laser performance can be set in $\%$ of maximum power. In experiments the laser outputs were: 25 , $40,50,75,100 \%$. The speed of laser is often influenced by the movement speed at that location. Thus experimental 


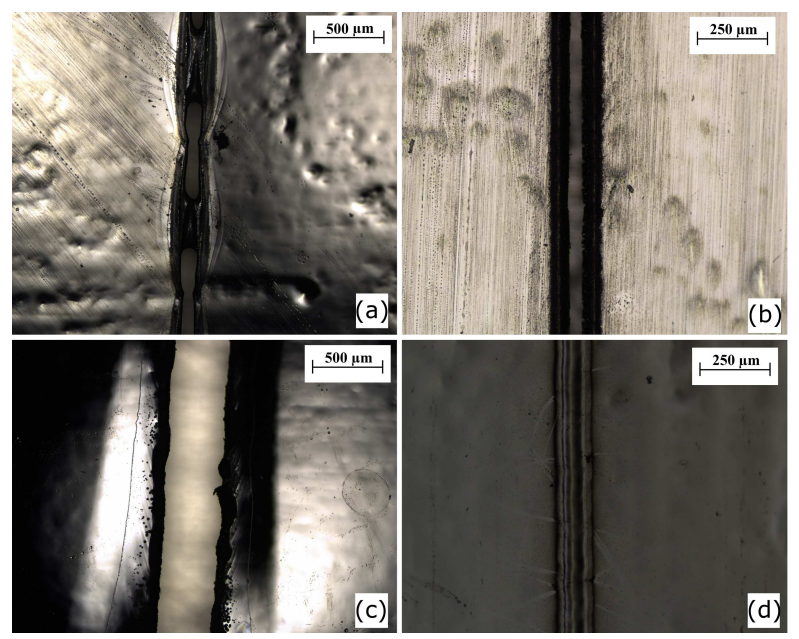

Fig. 1. Microscopic images of laser cut ribbon (a) $25 \%$ laser power, $0.1 \mathrm{~m} / \mathrm{s}, 1 \times$; (b) $40 \%$ laser power, $30 \mathrm{~m} / \mathrm{s}$, $1200 \times$; (c) $75 \%$ laser power, $0.1 \mathrm{~m} / \mathrm{s}, 1 \times$; (d) $100 \%$ laser power, $1 \mathrm{~m} / \mathrm{s}, 1 \times$.

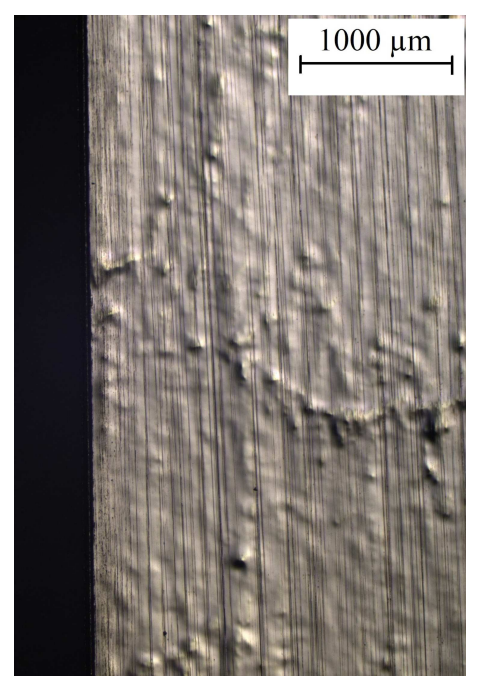

Fig. 2. Microscopic images of laser cut edge with optimal parameter.

values of speed used in our experiments were equal $0.1,1$, and $30 \mathrm{~m} / \mathrm{s}$. Preliminary experiments have shown that it is necessary to introduce a new parameter for the perfect cut to see how many times along the line the laser will run. If the laser went through a line only once, then too much power had to be used to make the cut. However, if one travels through the same line several times, the speed and performance could be optimized then.

Figure 1 shows microscopic images of the surface of the cuts made with the main test parameters. Figure 1a shows that even smaller laser power could not cut the tape completely even in the slowest motion. In turn, the signs indicating a heat effect zone can be observed. Figure 1b shows that a $40 \%$ laser power, at high scan speed along a line of 1200 times the cut edge surface,

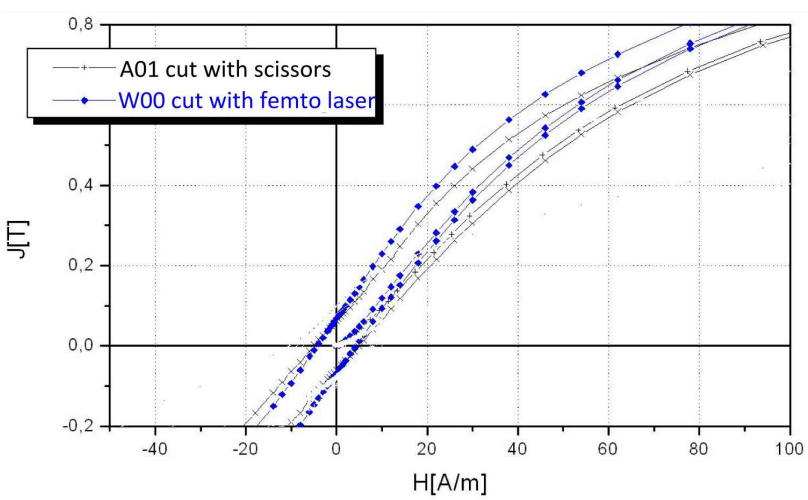

Fig. 3. The middle of the magnetization curve of METGLAS $\left(\mathrm{Fe}_{78} \mathrm{Si}_{9} \mathrm{~B}_{13}\right)$ samples cut with scissors and femtosecond laser.

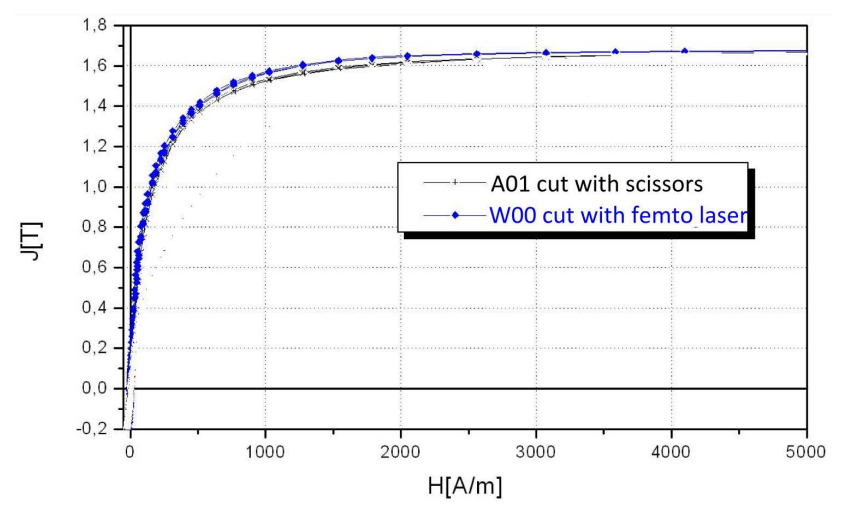

Fig. 4. The edge of the magnetization curve of METGLAS $\left(\mathrm{Fe}_{78} \mathrm{Si}_{9} \mathrm{~B}_{13}\right)$ samples cut with scissors and femtosecond laser.

is perfect. There is no visible heat zone. As shown in Fig. 1c, due to the increasing laser power, the material is completely burned, and a splash of spatter appears on the surface. In the case shown in Fig. 1d, the speed has been increased. No cutting has taken place, but the heat zone is clearly displayed. From the results it can be clearly determined that cutting is best done with multiple passages along the same line at medium speed with high scanning speed (Fig. 2).

After finding the optimal cutting parameter based on the microscope images, it is necessary to examine the effect of the cutting on the magnetic properties. Table I summarizes the magnetic properties of metal cut strips in different ways, i.e., by showing: saturation polarization $J_{s}[\mathrm{~T}]$, coercive force $H_{c}[\mathrm{~A} / \mathrm{m}]$, anisotropic constant $\mathrm{K}_{i}\left[\mathrm{~J} / \mathrm{m}^{3}\right]$, tension anisotropic constant $K_{\sigma}\left[\mathrm{J} / \mathrm{m}^{3}\right]$, demagnetizing factor $D \times 10^{5}$. Compared to the data from the literature, it can be seen that the parameters of cutting with the femtosecond laser are the most promising. The best of the literature results is the cut with mechanical scissors according to Table I. Therefore, these two cutting technologies will be compared later on in terms of magnetic properties. 
Magnetic properties of different cutting method of METGLAS $\left(\mathrm{Fe}_{78} \mathrm{Si}_{9} \mathrm{~B}_{13}\right)$ samples.

\begin{tabular}{l|c|c|c|c|c|cc}
\hline \hline \multicolumn{1}{c|}{ Type of cut } & $J_{s}[\mathrm{~T}]$ & $H_{c}[\mathrm{~A} / \mathrm{m}]$ & $K_{i}\left[\mathrm{~J} / \mathrm{m}^{3}\right]$ & $K_{\sigma}\left[\mathrm{J} / \mathrm{m}^{3}\right]$ & $D \times 10^{5}$ & Ref. \\
\hline scissors longitudinal & 1.695 & $4.97(4.62)$ & 828.4 & 774.7 & 9.13 & {$[11]$} \\
scissors transfer & 1.392 & 5.11 & 960.9 & 913.7 & 9.72 & {$[11]$} \\
waterjet & 1.48 & 6.64 & 1066.9 & 1007.9 & 10 & {$[12]$} \\
$\mathrm{CO}_{2}$ laser & 1.511 & 8.91 & 2832.7 & 2565.9 & 9.72 & {$[11]$} \\
femtosecond laser & 1.499 & 4.27 & 471.3 & 434.2 & 8.56 & present work
\end{tabular}

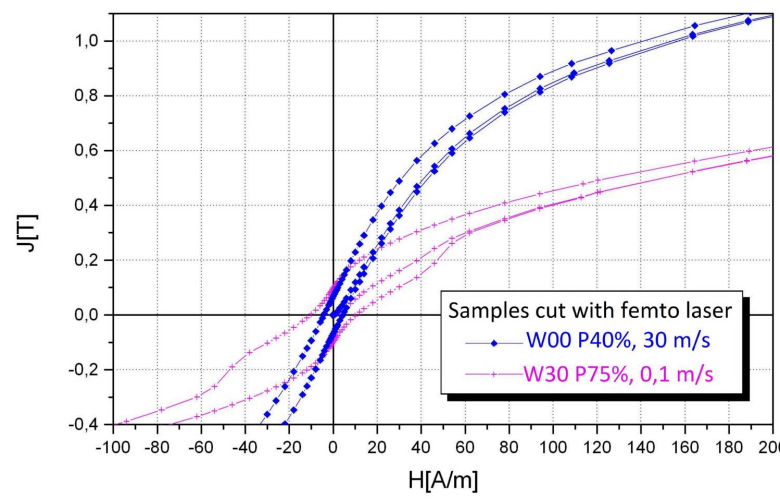

Fig. 5. The magnetization curve change due to deteriorating parameters.

Figures 3 and 4 show the magnetization curves of scissors, femtosecond laser cut off METGLAS $\left(\mathrm{Fe}_{78} \mathrm{Si}_{9} \mathrm{~B}_{13}\right)$ patterns. These two figures enlarge the various details of the curve up to the hysteresis, so that the differences between the two very running curves can be drawn. Two samples have very good magnet properties, i.e., their coercive forces are close (Table I) and virgin curves are almost identical (Fig. 3 and 4).

Figure 5 shows the magnetization curve of a metal strip cut with two different parameters. The square-marked curve with optimum laser parameters, and the high laser power marked with + , can be seen with slow laser movement. The hysteresis curve will not only flatten, but will be deformed, suggesting that there will be a significant change there.

\section{Conclusions}

It is expected that there will be a big future ahead of the use of metallic glass strips with good magnetic properties in electric motors. In order to be able to produce serial production with understood technology, many improvements are needed. One of the development processes is the development of cutting technology, for which the femtosecond laser presented in this article is a big step forward. On the basis of the results it can be stated that an optimal laser parameter has been set with which the cut surface is optimal, structural transformation, and there is hardly any change in the magnetizing properties. With the developed technology, the metal glass strips can be cut with good productivity so that their magnetic properties do not change.

\section{Acknowledgments}

I would like to specially thank Ladislav Novák (Department of Physics, Technical University of Košice) for the magnetic measurements.

This research is supported by EFOP-3.6.1-16-201600014 project. The Project is supported by the Hungarian Government and co-financed by the European Social Fund.

\section{References}

[1] A. Makino, Mater. Trans. 48, 3024 (2007).

[2] J. Wang, Scr. Mater. 65, 536 (2011).

[3] M. Shi, J. Mater. Sci. Technol. 31, 493 (2015).

[4] Z. LI, Intermetallics 54, 225 (2014).

[5] B. Vehovszky, T. Jakubík, M.Treszkai, Period. Polytech. Transp. Eng. 47, 190 (2019).

[6] P. Meagher, Adv. Mater. 28, 5755 (2016).

[7] P. Waide, "Energy-Efficiency Policy Opportunities for Electric Motor-Driven Systems", IEA, Paris 2011.

[8] H. Ryusuke, J. Magn.Magn. Mat. 100, 1 (1991).

[9] J. Kovac, B. Vehovszky, L. Novak, A. Lovas, IEEE Trans. Magnet. 46, 353 (2010).

[10] L. Novák, J. Kováč, L. Hubač, Acta Phys. Pol. A 131, 753 (2017).

[11] M. Nagy, K. Bán, Á. Cziráki, A. Szabó, Dunakavics VI(VIII), 17 (2018).

[12] D. Kóti, A. Szabó, A. Nagy, Á. Cziráki, in: Advanced Manufacturing and Repair Technologies in Vehicle Industry: Proc. 35th International Colloquium, Zielona Góra-Lagów Lubuski (Poland) 2018, Eds. F. Romankiewicz, R. Romankiewicz, R. Ulewicz, University of Zielona Góra, Faculty of Mechanical Engineering 2018, p. 151. 